\title{
Bias effects in facilitatory phonological priming
}

\author{
DENNIS NORRIS \\ MRC Cognition and Brain Sciences Unit, Cambridge, England \\ and \\ JAMES M. MCQUEEN and ANNE CUTLER \\ Max Planck Institute for Psycholinguistics, Nijmegen, The Netherlands
}

\begin{abstract}
In four experiments, we examined the facilitation that occurs when spoken-word targets rhyme with preceding spoken primes. In Experiment 1, listeners' lexical decisions were faster to words following rhyming words (e.g., ramp-LAMP) than to words following unrelated primes (e.g., pink-LAMP). No facilitation was observed for nonword targets. Targets that almost rhymed with their primes (foils; e.g., bulk-SULSH) were included in Experiment 2; facilitation for rhyming targets was severely attenuated. Experiments 3 and 4 were single-word shadowing variants of the earlier experiments. There was facilitation for both rhyming words and nonwords; the presence of foils had no significant influence on the priming effect. A major component of the facilitation in lexical decision appears to be strategic: Listeners are biased to say "yes" to targets that rhyme with their primes, unless foils discourage this strategy. The nonstrategic component of phonological facilitation may reflect speech perception processes that operate prior to lexical access.
\end{abstract}

The processing of spoken words is influenced by phonological overlap between those target words and preceding spoken primes. As we will describe in detail below, both facilitation and inhibition of processing have been observed. These effects, at least in part, have been taken to reflect the operation of different components of the speech recognition system. The facilitation that has been found when primes and targets rhyme has been interpreted as being due to the operation of prelexical processes-that is, the processes that precede lexical access. The inhibition that is observed when primes and targets begin in the same way has been considered to reflect competition between candidate words during the recognition process.

Phonological priming may therefore provide a useful methodological tool for studying the operation of various components of the speech recognition system. A concern that has been voiced repeatedly about phonological priming, however, is that it may reflect strategic processes, rather than the automatic processes associated with normal spoken-word recognition. It is therefore important to establish the extent to which this is true; conclusions about the processes and representations used in normal speech recognition can be drawn from phonological priming studies only if it can be shown that the effects are not due to

We thank Chris Wood and Sally Butterfield for assistance with the preparation and running of these experiments and Ian Nimmo-Smith for statistical advice. Correspondence concerning this article should be sent to D. Norris, MRC Cognition and Brain Sciences Unit, 15 Chaucer Road, Cambridge CB2 2EF, England (e-mail: dennis.norris@mrccbu.cam.ac.uk). strategies that listeners develop in the specific setting of priming experiments. A review of the literature on priming serves to illustrate this point. Effects differ depending on how much primes and targets overlap and on where that overlapping material is located.

First, consider the situation in which there is a small degree of initial overlap between primes and targets (i.e., they share only their first phoneme; e.g., bun-BACK). In this case, responses to targets are faster than in an unrelated condition (e.g., moon-BACK). This effect is not entirely robust (see, e.g., Radeau, Morais, \& Seguí, 1995, Appendix A, for an overview) but has been observed with reasonable consistency in the single-word shadowing task, in which listeners are required to repeat the target word after they hear it (Goldinger, 1999; Hamburger \& Slowiaczek, 1996; Slowiaczek \& Hamburger, 1992). It seems clear that this facilitation reflects a task-specific strategy. Subjects appear to learn that target words are likely to begin with the same segments as their primes; hence, they prepare the production of those segments and, thus, repeat the targets more rapidly (Goldinger, 1999; Hamburger \& Slowiaczek, 1999). The effect is not observed in the lexical decision task (Radeau, Morais, \& Dewier, 1989; Slowiaczek \& Hamburger, 1992; Slowiaczek \& Pisoni, 1986), except when materials are presented in noise and a relatively high proportion of related trials is included (Goldinger, 1998b; Goldinger, Luce, Pisoni, \& Marcario, 1992). Again, Goldinger et al. (1992) explained the facilitation they observed in terms of bias: Expectations of shared initial segments between primes and targets could benefit performance on targets in noise even when no naming response is required.

Second, when the amount of initial overlap of primes with targets increases, facilitation turns into inhibition (Slo- 
wiaczek \& Hamburger, 1992). Although the pattern of findings is again not entirely consistent (Radeau et al., 1995), responses to target words tend to be slower after primes beginning with the same few initial phonemes (e.g., brim-BRICK) than after unrelated primes (e.g., flapBRICK). This inhibition has been found both with shadowing (Goldinger, 1999; Hamburger \& Slowiaczek, 1996; Radeau et al., 1989; Slowiaczek \& Hamburger, 1992) and with lexical decision (Monsell \& Hirsh, 1998; Radeau et al., 1989). In other lexical decision experiments, nonsignificant inhibitory trends have been observed (Praamstra, Meyer, \& Levelt, 1994; Radeau et al., 1995; Slowiaczek \& Pisoni, 1986).

Multiple-phonemeonset overlap inhibition is not the result of task-specific strategies. It is, in fact, strongest when strategic confounding factors are minimized (Hamburger \& Slowiaczek, 1996; Monsell \& Hirsh, 1998). Instead, it appears to reflect automatic processes in the speech recognition system - specifically, competition between simultaneously activated candidate words. Lexical competition constitutes the core recognition mechanism in models of spoken-word processing (Gaskell \& Marslen-Wilson, 1997; Luce, Goldinger, Auer, \& Vitevitch, 2000; McClelland \& Elman, 1986; Norris, 1994), and it is supported by experimental evidence from many differing experimental paradigms: cross-modal associative priming (Zwitserlood, 1989), cross-modal identity priming (Vroomen \& de Gelder, 1995), cross-modal fragment priming (Soto-Faraco, Sebastián-Gallés, \& Cutler, 2001), eye tracking (Allopenna, Magnuson, \& Tanenhaus, 1998; Dahan, Magnuson, Tanenhaus, \& Hogan, 2001), word spotting (McQueen, Norris, \& Cutler, 1994; Norris, McQueen, \& Cutler, 1995), unprimed lexical decision, shadowing, and same-different judgment tasks (Luce \& Large, 2001; Vitevitch \& Luce, 1998, 1999), and phonetic priming (where primes and targets share phonetic features, but not phonemes; Goldinger, Luce, \& Pisoni, 1989; Goldinger et al., 1992; Luce et al., $2000)$. In the phonological priming case, words with a multiple-phoneme onset overlap (e.g., brim, brick) will be simultaneously activated by presentation of the onset. As more information arrives that causes one of them-say, brim - to win the competition, the others will lose and will suffer a penalty that will translate into inhibition if they then occur as a subsequent target.

Third, when primes and targets end in the same way, facilitation (e.g., faster responses to LAMP after ramp than after pink) has been consistently and repeatedly observed (Cutler \& Chen, 1995; Cutler, van Ooijen, \& Norris, 1999; Dumay, Benraïss, Barriol, Colin, Radeau, \& Besson, 2001; Emmorey, 1989; Monsell \& Hirsh, 1998; Praamstra et al., 1994; Radeau, Besson, Fontaneau, \& Castro, 1998; Radeau et al., 1995; Radeau, Seguí, \& Morais, 1994; Slowiaczek, McQueen, Soltano, \& Lynch, 2000; Slowiaczek, Nusbaum, \& Pisoni, 1987; Titone \& Connine, 1997). Finaloverlap facilitation appears to depend heavily, however, on whether the primes and the targets rhyme (i.e., share all phonemes from the stressed vowel to word offset). Slowiaczek et al. (2000) found some evidence within mono- syllabic prime-target pairs of facilitation between items that did not rhyme and showed that the amount of facilitation tended to depend on the amount of phonologicaloverlap between primes and targets (i.e., the number of shared phonemes, independently of whether the primes and the targets rhymed), but, at least when there was no material intervening between prime and target, there was always robust facilitation when the targets rhymed with their primes.

In studies that have examined bisyllabic prime-target pairs, the amount of facilitation increases with increasing phonologicaloverlap (Cutler \& Chen, 1995; Dumay et al., 2001; Emmorey, 1989); specifically, there tends to be stronger priming when primes and targets share the complete second syllable (e.g., lurage-TIRAGE; French examples from Dumay et al., 2001) than when they share only the rime (vowel plus final consonant[s]; e.g., lubageTIRAGE). Cutler et al. (1999) found priming for bisyllabic Dutch items that did not rhyme but did share either the second-syllable rimes (e.g., kamer-KAPER) or the entire second syllables (e.g., koper-KAPER). Taken together, these results suggest that there are two components to final-overlap facilitation: one that depends simply on the amount of phonological overlap, and one that depends on whether primes and targets rhyme.

Final-overlap facilitation has a number of properties that all suggest that it reflects prelexical processes involved in speech perception. First, facilitation is observed only when both the prime and the target are spoken; crossmodal presentation does not produce any facilitation (neither when the prime is spoken and the target is visual [Cutler et al., 1999; Radeau et al., 1994] nor the reverse [Dumay et al., 2001]). Second, it has been found not only in the shadowing task (e.g., Radeau et al., 1995), but also in tasks that do not require speech production, including lexical decision (e.g., Praamstra et al., 1994) and identification in noise (Slowiaczek et al., 1987). Furthermore, the facilitation has not been found in experiments on speech production. In implicit priming studies (Meyer, 1990, 1991), facilitation in naming latencies is found when the words in the response set begin in the same way, not when they end in the same way. In picture-word interference experiments (Meyer \& Schriefers, 1991), there is no facilitation if presentation of the picture to be named is preceded by presentation of an auditory distractor that rhymes with the picture name. In picture-picture naming, there is inhibitionif the two picture names rhyme (Sullivan \& Riffel, 1999). Finally, facilitation (unlike multiple-phoneme onset overlap inhibition) does not depend on the lexical status of the prime: Equivalent effects are found for word targets preceded by word or nonword primes (Cutler et al., 1999; Dumay et al., 2001; Monsell \& Hirsh, 1998; Slowiaczek et al., 2000). Furthermore, facilitation does not appear to depend on the relative frequency of occurrence of primes and targets (Radeau et al., 1995). These results suggest that lexical-level processes are not involved in the facilitation effect.

Although all of these results are consistent with the notion that final-overlap facilitation reflects automatic prelex- 
ical processes, it remains possible that this facilitation, at least in part, may be due to strategic processes. In the present experiments, this issue was examined. Results to date suggest that there is a strategic component to the facilitation effect, but the findings are inconclusive. Slowiaczek et al. (2000) varied the number of related trials in a shadowing experiment and found a trend toward greater facilitation when there were more related trials (an effect that was significant by subjects, but not by items). In timeordered analyses of responses in unrelated trials, however, Slowiaczek et al. (2000) found no evidence of a bias emerging over the course of any of their four shadowing experiments. Furthermore, they consistently found priming in experiments in which the proportion of rhyming trials was $10 \%$ (and the total proportion of related trials was no more than $25 \%$ ). It is possible, however, that facilitation could be due to a bias that emerges rapidly and remains stable over an experiment and that does not depend on a high proportion of related trials. Another piece of evidence that is suggestive of a strategic component in facilitation is that it has a very short time course. In experiments using continuous lexical decision (Cutler et al., 1999; Monsell \& Hirsh, 1998; Slowiaczek et al., 2000), facilitation disappears rapidly as the lag between the prime and the target (i.e., the number of intervening items) increases. This might suggest that the facilitation depends on the explicit detection of the rhyming relationship between the prime and the target. On the other hand, however, this may indicate a short-lived automatic facilitatory process.

A stronger piece of evidence that final-overlap facilitation may have a strategic component is the finding that, whereas robust facilitation is found for word targets in lexical decision, there tends to be only weak facilitation or none at all for nonword targets (Monsell \& Hirsh, 1998). If facilitation is due to an automatic prelexical process, it ought not to depend on the lexical status of the target (just as it appears not to depend on the lexical status of the prime). If, however, it is due to a bias in lexical decisions, it could well be detectable in "yes" decisions, but not in "no" decisions. That is, a bias to say "yes" to items that rhyme would have an inhibitory effect on correct responses to rhyming nonword targets, masking any facilitatory effect (owing to automatic processes) in "no" decisions. There may, therefore, be a strategic component of final-overlap priming that is specific to the lexical decision task. One aim of the present experiments was thus to compare lexical decision and shadowing, using the same materials, and to measure performance on both word and nonword targets.

The primary purpose of these experiments, however, was to explicitly test for the presence of a response bias. We did this by using foils - that is, targets that almost rhymed with their primes (e.g., bulk-SULSH). If, in lexical decision, listeners develop a bias to say "yes" to targets that rhyme with their primes or a bias to respond early to targets that sound as though they will rhyme with their primes, they should be discouraged from using such a strategy when foils like this are included in the experiment. In Experiment 1 , therefore, we ran a standard phonologicalpriming experiment, using the lexical decision task. Listeners made "yes" decisions to words preceded by either rhyming or nonrhyming words (e.g., ramp-LAMP and pink-LAMP) and "no" decisions to nonwords preceded by either rhyming or nonrhyming words (e.g., month-LUNTH and waspLUNTH). All the primes were words, $25 \%$ of the trials were related (12.5\%, ramp-LAMP; $12.5 \%$, month-LUNTH), and there were no foils. Experiment 2 was identical, except that $25 \%$ of the unrelated trials in Experiment 1 were replaced by trials with foils. On half of these trials, word targets were preceded by primes with which they almost rhymed (e.g., film-KILT). Note that kilm is not a word. If subjects were to anticipate the rhyming item kilm after the prime film, this would lead to an incorrect "no" decision. Likewise, on the other half of the foil trials, nonword targets were preceded by primes with which they almost rhymed (e.g., bulk-SULSH). Anticipation based on rhyme here (i.e., the word sulk) would lead to an incorrect "yes" decision. The critical question was whether the presence of these foil trials would influence performance on the targets that did rhyme with their primes.

\section{EXPERIMENT 1}

\section{Method}

Subjects. The subjects were 24 members of the MRC Cognition and Brain Sciences volunteer panel, who were paid for their participation.

Materials. All the stimuli were monosyllables with a CVCC structure. The prime was always a word. Fifty percent of the targets were words, and the rest were nonwords. The experimental stimuli were derived from 48 rhyming word-word pairs and 48 rhyming wordnonword pairs (see the Appendix). Rhyming pairs always shared their final VCC. Unrelated pairs were constructed by rearranging the assignment of primes and targets within conditions. The mean frequency of word targets was 5.04 per million (CELEX English lexicon; Burnage, 1990), although 16 of the 48 word targets had frequencies of 0 or 1 (i.e., in order to generate enough CVCC items, we had to use some low-frequency words, including several inflected forms). The mean duration of word targets was $475 \mathrm{msec}$, and that of nonword targets was $480 \mathrm{msec}$.

There were two experimental presentation lists, constructed so that half of the targets in each word and nonword set appeared in a related condition and half in an unrelated condition. The lists were counterbalanced so that, over the two lists, all the targets appeared in both a related and an unrelated condition. Each experimental list also contained 96 filler items, half of which had word targets, and half of which had nonword targets. In this experiment, all of the filler items were unrelated.

Procedure. The stimuli were recorded onto digital audio tape in a soundproof cubicle, using a high-quality microphone. They were then transferred digitally to a computer and were downsampled to $22.05 \mathrm{kHz}$. The stimuli were excised from these recordings, using a waveform editor, and the onsets of all the target stimuli were marked. Finally, the stimuli were converted to stereo files with a timing pulse on one channel and the speech on the other and were transferred to compact disk to create the two counterbalanced presentation lists. Silent intervals were inserted between items so that there was an interstimulus interval of $50 \mathrm{msec}$ between the prime and the target and a 2-sec intertrial interval.

The stimuli were presented to subjects via Sennheiser HD250 headphones driven by a Sony portable CD player and a high-quality headphone amplifier. Reaction times (RTs), measured from stimu- 
lus onset, were recorded by a Toshiba portable computer running the TSCOP timing software (Norris, 1984). The subjects were tested individually in a quiet room. Each experimental list consisted of 16 practice trials, followed by three blocks of 52 trials. The first 4 trials in each block were buffer trials. The subjects were allowed a brief rest between blocks. They were instructed to decide as quickly as possible whether the targets were words or nonwords and to press a button labeled "yes" if the target was a word and one labeled "no" if the target was a nonword.

\section{Results and Discussion}

Seven items were removed from this and all subsequent analyses because these items produced error rates greater than $33 \%$ in all conditions (length, salve, kelp, fund, vank, fump, and fank). The results are shown in Table 1. The main effect of priming was significant both by subjects and by items $\left[F_{1}(1,22)=81.39, M S_{\mathrm{e}}=78,403, p<.001 ; F_{2}(1,84)=\right.$ 93.28, $\left.M S_{\mathrm{e}}=168,045, p<.001\right]$. Responses were, on average, $58 \mathrm{msec}$ faster when the target rhymed with the prime than when it did not. The main effect of lexicality was also significant $\left[F_{1}(1,22)=66.86, M S_{\mathrm{e}}=191,022, p<\right.$ $\left..001 ; F_{2}(1,84)=36.07, M S_{\mathrm{e}}=301,308, p<.001\right]$. Responses to word targets were $90 \mathrm{msec}$ faster, on average, than to nonword targets. There was also a significant interaction between priming and lexicality $\left[F_{1}(1,22)=\right.$ $73.42, M S_{\mathrm{e}}=88,463, p<.001 ; F_{2}(1,84)=99.87, M S_{\mathrm{e}}=$ $179,920, p<.001]$, reflecting the fact that the priming effect was restricted to the word stimuli $(118 \mathrm{msec})$. For nonwords, the difference was only $3 \mathrm{msec}$.

The pattern of results in the error data closely parallels that in the latency data, with a small but significant effect of priming [responses were $2 \%$ more accurate, on average, when targets rhymed with their primes than when they $\operatorname{did}$ not; $F_{1}(1,22)=5.41, M S_{\mathrm{e}}=0.0168, p<.05 ; F_{2}(1,84)=$ $\left.6.13, M S_{\mathrm{e}}=0.0308, p<.05\right]$ and a significant interaction between priming and lexicality $\left[F_{1}(1,22)=10.65, M S_{\mathrm{e}}=\right.$ $\left.0.0298, p<.005 ; F_{2}(1,84)=10.83, M S_{\mathrm{e}}=0.0545, p<.005\right]$. As in the latency data, the priming effect was restricted to the word targets $(6 \%)$. In fact, there were marginally more errors $(1 \%)$ to related nonwords than to unrelated nonwords. The main effect of lexicality was significant in the subjects analysis, but just failed to reach significance in the items analysis $\left[F_{1}(1,22)=5.90, M S_{\mathrm{e}}=0.0247, p<.05 ; F_{2}(1,84)=\right.$ $\left.3.76, M S_{\mathrm{e}}=0.0452, p=.056\right]$.

\section{Table 1}

Mean Reaction Times (RTs, in Milliseconds, Measured From Item Onset) and Mean Percentage Errors for Lexical Decisions to Target Words and Nonwords in Experiments 1 and 2

\begin{tabular}{|c|c|c|c|c|}
\hline \multirow[b]{2}{*}{ Measure } & \multicolumn{2}{|c|}{ Word Target } & \multicolumn{2}{|c|}{ Nonword Target } \\
\hline & $\begin{array}{c}\text { Rhyming } \\
\text { Prime }\end{array}$ & $\begin{array}{l}\text { Unrelated } \\
\text { Prime }\end{array}$ & $\begin{array}{c}\text { Rhyming } \\
\text { Prime }\end{array}$ & $\begin{array}{c}\text { Unrelated } \\
\text { Prime } \\
\end{array}$ \\
\hline \multicolumn{5}{|c|}{ Experiment 1: No Foils } \\
\hline RT & 702 & 820 & 852 & 849 \\
\hline Error & 5.4 & 11.6 & 5.7 & 4.8 \\
\hline \multicolumn{5}{|c|}{ Experiment 2: Foils } \\
\hline RT & 758 & 785 & 880 & 873 \\
\hline Error & 6.4 & 8.7 & 7.6 & 5.2 \\
\hline
\end{tabular}

The results of Experiment 1 are very clear. There was a reliable rhyme priming effect for words, but not for nonwords. This result is consistent both with previous findings and with the suggestion that the priming effect is due to subjects adopting a strategy that biases them toward making fast "yes" responses to rhyming words. In Experiment 2, we examined what happens when we attempt to discourage such a strategy by replacing $50 \%$ of the filler items used in Experiment 1 with foils.

\section{EXPERIMENT 2}

\section{Method}

Subjects. Twenty-four members of the MRC Cognition and Brain Sciences volunteer panel were paid for their participation. None of them had taken part in Experiment 1.

Materials and Procedure. The materials and procedure were identical to those in Experiment 1, except for the fact that the pairing of primes and targets in half of the filler items was reassigned to produce foil trials. Foil items were constructed in order to ensure that the subjects had to wait until the end of the stimulus before being able to respond accurately. Nonword foil trials consisted of pairs, such as bulk-SULSH, that shared the vowel (V) and the first coda consonant $\left(\mathrm{C}_{1}\right)$ but differed at the final consonant $\left(\mathrm{C}_{2}\right)$. If the subjects were to assume that stimuli sharing $\mathrm{VC}_{1}$ would, in fact, go on to share the whole $\mathrm{VC}_{1} \mathrm{C}_{2}$ rime, they would assume that SULSH would continue as the word sulk and would thus incorrectly classify sulsh as a word. Conversely, word foils consisted of pairs like film-KILT, so that, if the subjects were to anticipate that stimuli sharing the $\mathrm{VC}_{1}$ would go on to rhyme, they would incorrectly classify the word kilt as a nonword (kilm). The foil conditions contained 24 word foils and 24 nonword foils, which are listed in the Appendix. Note that four of the foil targets diverged from the prime on $\mathrm{C}_{1}$ (in meant-benk, hence-tenk, wand-fonk, and mint-hink, $\mathrm{C}_{1}$ is $/ \mathrm{n} /$ in the prime and $/ \mathrm{n} /$ in the target) and would therefore have been slightly less effective foils than the rest.

\section{Results and Discussion}

The results of Experiment 2 are shown in Table 1. In comparison with Experiment 1, the priming effect in Experiment 2 was greatly reduced. In the latency analysis, the overall priming effect (only $10 \mathrm{msec}$, on average) was no longer significant $\left[F_{1}(1,22)=1.76, M S_{\mathrm{e}}=2,205, p>.1\right.$; $\left.F_{2}(1,84)=3.28, M S_{\mathrm{e}}=6,353, p>.05\right]$. Responses to target words were significantly faster than those to target nonwords [105 msec, on average; $F_{1}(1,22)=101.1, M S_{\mathrm{e}}=$ $264,119, p<.001 ; F_{2}(1,84)=45.2, M S_{\mathrm{e}}=453,685, p<$ $.001]$. Although the interaction between priming and lexicality was significant only by items $\left[F_{1}(1,22)=3.09\right.$, $M S_{\mathrm{e}}=6,651, p>.05 ; F_{2}(1,84)=6.18, M S_{\mathrm{e}}=11,976, p<$ $.05]$, the priming effect in an analysis of the words alone (27 msec, on average) was significant $\left[F_{1}(1,22)=5.13\right.$, $M S_{\mathrm{e}}=8,259, p<.05 ; F_{2}(1,41)=10.02, M S_{\mathrm{e}}=17,498, p<$ $.005]$.

In the error analysis, the only effect to reach significance was the interaction between priming and lexicality, which was significant only by items $\left[F_{1}(1,22)=3.76, M S_{\mathrm{e}}=\right.$ $\left.0.0137, p>.05 ; F_{2}(1,84)=4.71, M S_{\mathrm{e}}=0.0251, p<.05\right]$. Neither the main effect of priming $(F \mathrm{~s}<1)$ nor that of lexicality $\left[F_{1}(1,22)=1.1, M S_{\mathrm{e}}=0.0032, p>.1 ; F_{2}(1,84)<1\right]$ was significant. 
A combined analysis of the latency data from Experiments 1 and 2 showed that the priming effect became significantly weaker in Experiment 2 [i.e., the interaction of the priming effect with experiment was highly significant; $F_{1}(1,44)=24.51, M S_{\mathrm{e}}=27,163, p<.001 ; F_{2}(1,84)=$ $\left.34.73, M S_{\mathrm{e}}=54,530, p<.001\right]$. Given that the priming effect in both experiments was restricted entirely to the words, there was also an interaction between experiment, priming, and lexicality $\left[F_{1}(1,44)=13.87, M S_{\mathrm{e}}=23,296, p<\right.$ $\left..001 ; F_{2}(1,84)=31.52, M S_{\mathrm{e}}=49,501, p<.001\right]$. In a combined analysis of the errors in each experiment, the twoway interaction between experiment and priming was significant only by items $\left[F_{1}(1,44)=2.71, M S_{\mathrm{e}}=0.0088, p>\right.$ $\left..1 ; F_{2}(1,84)=4.00, M S_{\mathrm{e}}=0.0162, p<.05\right]$, and the threeway interaction between experiment, priming, and lexicality was not significant by either subjects or items $\left(F_{\mathrm{S}}<1\right)$.

One might be concerned that responses on unrelated word trials actually appear to speed up when foils are included. Perhaps much of the effect of foils on priming is actually being carried by changes in responses to unrelated targets. The change in latency on the unrelated word targets between Experiment 1 and Experiment 2 was significant only by items $\left[F_{1}(1,44)=1.60, M S_{\mathrm{e}}=14,998, p>.2\right.$; $\left.F_{2}(1,41)=14.28, M S_{\mathrm{e}}=39,767, p<.001\right]$. The corresponding difference in error rates was not significant $\left[F_{1}(1,44)=1.82, M S_{\mathrm{e}}=0.0096, p>.1 ; F_{2}(1,41)=2.67\right.$, $\left.M S_{\mathrm{e}}=0.0171, p>.1\right]$. It is important to note, however, that this trend toward faster responses on unrelated words in the presence of foils is what should be expected if the foils reduce the subjects' "yes" bias on rhyming targets. Any tendency to respond "yes" to rhyming targets would be accompanied by a tendency to respond "no" to nonrhyming targets. Responses to unrelated word targets should therefore be faster in the presence of foils, because any bias to make an incorrect "no" response to such targets will decrease. This account also predicts that responses to unrelated nonword targets will tend to get slower in the presence of foils. This is because there would be a decrease in the bias to make a "no" response to these items in the presence of foils. Responses to unrelated nonword targets were indeed slower (and less accurate) in Experiment 2 than in Experiment 1, although these trends were not significant [RTs, $F_{1}<1$ and $F_{2}(1,43)=1.83, M S_{\mathrm{e}}=5,684, p>$ .1 ; errors, both $F \mathrm{~s}<1]$.

We can get some indication of the effect of the foil manipulation on the filler items themselves by comparing the items that changed from no-foil to foil items between experiments with the fillers that were always unrelated to their primes. The foil data for Experiments 1 and 2 are shown in Table 2. As might be expected, the difference between the "foil" items and the remaining fillers increased when the "foil" items really were foils in Experiment 2. Responses to the foil items were $12 \mathrm{msec}$ faster, on average, than those to the filler items in Experiment 1, but when the foils were actually foils (in Experiment 2), responses to them were, on average, $15 \mathrm{msec}$ slower than those to the fillers. This interaction between filler type and experiment was significant both by subjects and by items in the la-
Table 2

Mean Reaction Times (RTs, in Milliseconds, Measured From Item Onset) and Mean Percentage Errors for Lexical Decisions to Filler Words and Nonwords in Experiments 1 and 2

\begin{tabular}{|c|c|c|c|c|}
\hline \multirow[b]{2}{*}{ Measure } & \multicolumn{2}{|c|}{ Word Target } & \multicolumn{2}{|c|}{ Nonword Target } \\
\hline & Foil & Filler & Foil & Filler \\
\hline \multicolumn{5}{|c|}{ Experiment 1: No Foils } \\
\hline RT & 835 & 847 & 886 & 887 \\
\hline Error & 23.3 & 16.0 & 5.9 & 4.3 \\
\hline \multicolumn{5}{|c|}{ Experiment 2: Foils } \\
\hline RT & 874 & 859 & 905 & 890 \\
\hline Error & 25.0 & 17.5 & 11.6 & 7.8 \\
\hline
\end{tabular}

Note- "Foils" were foils only in Experiment 2; in Experiment 1, they were preceded by unrelated primes.

tency analysis $\left[F_{1}(1,44)=7.56, M S_{\mathrm{e}}=5,583, p<.01\right.$; $\left.F_{2}(1,92)=5.35, M S_{\mathrm{e}}=8,211, p<.05\right]$, but not in the error analysis $(F \mathrm{~s}<1)$. This indicates that, despite the presence of the foils, the subjects did still have some bias to assume that the targets would rhyme with the prime. Foil trials (e.g., film-KILT and bulk-SULSH) would therefore be responded to more slowly, since the subjects would be biased to make the wrong response. Although fillers were responded to more slowly overall in Experiment 2, the main effect of experiment was significant only in the items analysis $\left[F_{1}<1 ; F_{2}(1,92)=9.09, M S_{\mathrm{e}}=13,959, p<.005\right]$. However, the increased error rate in Experiment 2, as compared with Experiment 1 , was significant $\left[F_{1}(1,44)=\right.$ $5.41, M S_{\mathrm{e}}=0.0469, p<.05 ; F_{2}(1,92)=9.09, M S_{\mathrm{e}}=$ $13,959, p<.005]$. Note also that the error rates on the filler items were higher in both experiments than those on the experimental items. This is because we did not apply an exclusion criterion to the nonexperimentalitems. Like the experimental items, the filler and foil sets included some low-frequency words to which several listeners responded "no" (six foils and three filler items had error rates greater than $33 \%)$.

The addition of foil materials to Experiment 2, therefore, greatly attenuated the facilitatory effect that had been observed for rhyming word targets in Experiment 1. This suggests that there is a strong strategic component to rhyme priming. The fact that the effect in Experiment 1 was limited to word targets is also consistent with this account: A bias to say "yes" to rhyming items will produce facilitation for word targets but inhibition for nonword targets. The pattern of results therefore indicates that there may be both strategic and automatic components in rhyme priming. These two components appear to work together to produce a large $(>100 \mathrm{msec})$ priming effect for word targets but to work against each other to produce neither facilitation nor inhibition for nonword targets. If the effect in Experiment 1 had been purely strategic, inhibition would have been expected on the nonword targets.

This leads to a straightforward prediction: If the strategy is specific to the lexical decision task, it should be possible to observe facilitation for rhyming nonwords (as well as words) in a task that does not induce this kind of strat- 
egy. Note that the absence of facilitation for nonwords in Experiment 2, in which the foils discouraged the use of a strategic bias, is not inconsistent with this prediction. It may be that the process of making "no" decisions cannot benefit (and may indeed be inhibited) by the automatic processes underlying the facilitation of "yes" responses. We return to this issue in the General Discussion section. Furthermore, foils may, in turn, induce other strategies (such as a phonological checking strategy), which could, in turn, mask any automatic facilitation effects (for both word and nonword targets). In Experiment 3, therefore, we used the materials from Experiment 1 in the single-word shadowing task. The subjects had to repeat aloud the target items. If the strategy in lexical decision is a bias to say "yes" to rhyming items, the subjects will not be able to use this bias in shadowing. Equal facilitation should therefore be found for word and nonword targets.

\section{EXPERIMENT 3}

\section{Method}

Subjects. The subjects were again 24 members of the MRC Cognition and Brain Sciences volunteer panel. They had not taken part in either of the earlier experiments and were paid for their participation.

Materials and Procedure. Experiment 3 used the same materials as those in Experiment 1. The subjects wore a microphone mounted on headphones, and their spoken responses triggered a voice-operated relay. The subjects were instructed to repeat the second item of each pair as quickly as possible.

\section{Results and Discussion}

The results of Experiment 3 are shown in Table 3. In the analysis of RTs, there was a highly significant effect of priming. Responses to targets were, on average, $27 \mathrm{msec}$ faster after primes with which they rhymed than after unrelated primes $\left[F_{1}(1,22)=30.68, M S_{\mathrm{e}}=17,495, p<\right.$ $\left..001 ; F_{2}(1,84)=26.02, M S_{\mathrm{e}}=28,394, p<.001\right]$. This priming effect was equivalent for word and nonword targets $\left[F_{1}(1,22)=2.49, M S_{\mathrm{e}}=563, p>.1 ; F_{2}(1,84)=1.39, M S_{\mathrm{e}}=\right.$ $1,518, p>.2]$. The main effect of lexicality was also significant [responses were faster to words than to nonwords; $F_{1}(1,22)=17.67, M S_{\mathrm{e}}=14,185, p<.001 ; F_{2}(1,84)=4.57$, $\left.M S_{\mathrm{e}}=28,550, p<.05\right]$. In the error analysis, there was no effect of priming $(F \mathrm{~s}<1)$ and no interaction between

Table 3

Mean Reaction Times (RTs, in Milliseconds, Measured From Item Onset) and Mean Percentage Errors for Shadowing Target Words and Nonwords in Experiments 3 and 4

\begin{tabular}{|c|c|c|c|c|}
\hline \multirow[b]{2}{*}{ Measure } & \multicolumn{2}{|c|}{ Word Target } & \multicolumn{2}{|c|}{ Nonword Target } \\
\hline & $\begin{array}{c}\text { Rhyming } \\
\text { Prime }\end{array}$ & $\begin{array}{l}\text { Unrelated } \\
\text { Prime }\end{array}$ & $\begin{array}{c}\text { Rhyming } \\
\text { Prime }\end{array}$ & $\begin{array}{c}\text { Unrelated } \\
\text { Prime } \\
\end{array}$ \\
\hline \multicolumn{5}{|c|}{ Experiment 3: No Foils } \\
\hline RT & 650 & 682 & 680 & 702 \\
\hline Error & 4.4 & 5.1 & 6.3 & 7.2 \\
\hline \multicolumn{5}{|c|}{ Experiment 4: Foils } \\
\hline RT & 704 & 721 & 740 & 755 \\
\hline Error & 4.7 & 2.3 & 4.4 & 6.1 \\
\hline
\end{tabular}

priming and lexicality $\left(F_{\mathrm{s}}<1\right)$. The effect of lexicality itself (more accurate responses to words than to nonwords) was significant only in the subjects analysis $\left[F_{1}(1,22)=\right.$ $7.73, M S_{\mathrm{e}}=0.0094, p<.05 ; F_{2}(1,84)=3.62, M S_{\mathrm{e}}=0.0173$, $p>.05]$.

In contrast to Experiment 1, the shadowing task produced a much smaller effect of priming, which was similar in magnitude for words and nonwords. Interestingly, the priming effect in Experiment 3 is very similar to the priming effect for words seen in Experiment 2. This raises the possibility that, when steps are taken to eliminate strategic effects, the priming effect observed for words in the lexical decision task is identical to that seen for both words and nonwords in the shadowing task. We suggested earlier that the lexical decision task might actually lead to an underestimation of the underlying phonological priming effect for nonwords. Any real priming effect might be masked by a bias to respond "yes" to primed items. Any such decision bias should not have an effect in the shadowing task.

This conclusion rests, however, on the assumption that there are no strategic effects in shadowing. Even though Meyer $(1990,1991)$ has shown that facilitation in an implicit priming study is found when the words in the response set begin in the same way, but not when they end in the same way, and has thus argued that facilitation depends on subjects' being able to prepare the articulation of word onsets, it is possible that strategies based on rhyme overlap might also play a role in shadowing. Subjects might be able to plan the rhyme of a target item on the basis of the rhyme of the prime. To determine whether strategic effects might also be at work in shadowing, we repeated Experiment 3 using the materials from Experiment 2 (including, crucially, the foil items).

\section{EXPERIMENT 4}

\section{Method}

Subjects. The subjects were another 24 members of the MRC Cognition and Brain Sciences volunteer panel, who were paid for their participation.

Materials and Procedure. Experiment 4 used the same materials and procedure as those in Experiment 2, with the exception that the task, as in Experiment 3, was shadowing.

\section{Results and Discussion}

The results of Experiment 4 are shown in Table 3. The data are very similar to those of Experiment 3 . In the analysis of RTs, there was again a significant effect of priming. Responses to targets were, on average, $16 \mathrm{msec}$ faster after primes with which they rhymed than after unrelated primes $\left[F_{1}(1,22)=10.78, M S_{\mathrm{e}}=6,530, p<.005 ; F_{2}(1,84)=\right.$ $\left.14.77, M S_{\mathrm{e}}=12,129, p<.001\right]$. There was again no interaction between priming and lexicality $\left(F_{\mathrm{S}}<1\right)$. The main effect of lexicality was significant $\left[F_{1}(1,22)=41.68\right.$, $M S_{\mathrm{e}}=30,062, p<.001 ; F_{2}(1,84)=7.02, M S_{\mathrm{e}}=53,162$, $p<.01]$. In the analysis of errors, there was no effect of priming $(F \mathrm{~s}<1)$ or lexicality $\left[F_{1}(1,22)=3.48, M S_{\mathrm{e}}=\right.$ $\left.0.0079, p>.05 ; F_{2}(1,84)=2.57, M S_{\mathrm{e}}=0.0144, p>.1\right]$, but 
there was a significant interaction between the two $\left[F_{1}(1,22)=5.61, M S_{\mathrm{e}}=0.0099, p<.05 ; F_{2}(1,84)=5.91\right.$, $\left.M S_{\mathrm{e}}=0.0182, p<.05\right]$.

To determine whether the inclusion of foil trials significantly altered the pattern of priming, we performed a combined analysis of the data from Experiments 3 and 4. In the combined analysis, there was no significant interaction between priming and experiment $\left[\mathrm{RTs}, F_{1}(1,44)=\right.$ $2.27, M S_{\mathrm{e}}=1,333, p>.1$, and $F_{2}(1,84)=2.40, M S_{\mathrm{e}}=1,711$, $p>.1$; errors, $F \mathrm{~s}<1]$ and no interaction between priming, lexicality, and experiment [RTs, $F_{1}<1$ and $F_{2}(1,84)=$ $1.08, M S_{\mathrm{e}}=772, p>.3$; errors, $F_{1}(1,44)=2.10, M S_{\mathrm{e}}=$ $0.0045, p>.1$, and $\left.F_{2}(1,84)=2.03, M S_{\mathrm{e}}=0.0082, p>.1\right]$. There was, however, a main effect of experiment in the latency analysis, significant only by items $\left[F_{1}(1,44)=3.29\right.$, $M S_{\mathrm{e}}=128,229, p<.1 ; F_{2}(1,84)=190.47, M S_{\mathrm{e}}=247,349$, $p<.001]$. As is to be expected with an item analysis corresponding to a between-subjects factor in which there is even a small difference between subject groups, the effect by items can be highly significant. There was no effect of experiment in the error analysis $\left[F_{1}(1,44)=2.25, M S_{\mathrm{e}}=\right.$ $\left.0.0089, p>.1 ; F_{2}(1,84)=3.39, M S_{\mathrm{e}}=0.0163, p<.1\right]$. The trend toward slower responses in all the conditions of Experiment 4 suggests that the presence of foils increased task difficulty. This pattern of results stands in contrast to that obtained when comparing Experiments 1 and 2, where responses tended to become faster on unrelated word targets and slower on unrelated nonword targets when foils were included (but note that these differences also were not fully reliable). The differences in these trends between tasks are consistent with the hypothesis that the presence of foils changed the listeners' response strategy in lexical decision, but not in shadowing. The foil manipulation influenced the relative difficulty of responding to unrelated words versus unrelated nonwords in lexical decision but had no such effect on the difficulty of shadowing.

Table 4 shows the data for the filler items. Although the general pattern of results is similar to that seen in the lexical decision data, in that filler items were responded to more slowly and less accurately when they were foils, the interactions between foil type and experiment were not significant either for latencies $\left(F_{\mathrm{S}}<1\right)$ or for errors $\left[F_{1}(1,44)=\right.$

Table 4

Mean Reaction Times (RTs, in Milliseconds, Measured From Item Onset) and Mean Percentage Errors for Shadowing Filler Words and Nonwords in Experiments 3 and 4

\begin{tabular}{lccccc}
\hline & \multicolumn{2}{c}{ Word Target } & & \multicolumn{2}{c}{ Nonword Target } \\
\cline { 2 - 3 } \cline { 5 - 5 } Measure & Foil & Filler & & Foil & Filler \\
\hline \multirow{5}{*}{ RT } & 664 & 683 & 703 & 713 \\
Error & 3.1 & 3.8 & 5.0 & 6.9 \\
& \multicolumn{3}{c}{ Experiment 3: No Foils } \\
RT & 732 & 748 & 758 & 779 \\
Error & 3.8 & 1.7 & 6.4 & 7.3 \\
\hline
\end{tabular}

Note- "Foils" were foils only in Experiment 4; in Experiment 3, they were preceded by unrelated primes.
$2.52, M S_{\mathrm{e}}=0.0044, p>.1 ; F_{2}(1,92)=1.91, M S_{\mathrm{e}}=0.0044$, $p>$.1]. However, there were large effects of lexicality for both latencies $\left[F_{1}(1,44)=99.29, M S_{\mathrm{e}}=48,029, p<.001\right.$; $\left.F_{2}(1,92)=8.83, M S_{\mathrm{e}}=47,938.7200, p<.005\right]$ and errors $\left[F_{1}(1,44)=21.02, M S_{\mathrm{e}}=0.0522, p<.001 ; F_{2}(1,92)=\right.$ $\left.7.90, M S_{\mathrm{e}}=0.0522, p<.01\right]$ and a significant effect of experiment in the latency analysis $\left[F_{1}(1,44)=4.34, M S_{\mathrm{e}}=\right.$ $194,155, p<.05 ; F_{2}(1,92)=368.65, M S_{\mathrm{e}}=197,165.3746$, $p<.0001]$, but not in errors $\left(F_{1}<1 ; F_{2}<1\right)$.

In contrast to lexical decision, therefore, the phonological priming effect in shadowing was not significantly influenced by the presence of foils. Numerically, however, there was a reduction in the amount of priming, especially for words. For word targets, the presence of foils reduced the priming effect to about half the size it was without foils. Although this is proportionally smaller than the effect of foils in lexical decision, in which foils reduce priming by $77 \%$ (or $92 \mathrm{msec}$ ), it does make it impossible to conclude that there are no strategic effects in shadowing. However, the $95 \%$ confidence limits on the $14-\mathrm{msec}$ priming-by-foil interaction for words are $\pm 16 \mathrm{msec}$. In contrast, the same confidence limits on the 92-msec priming-by-foil interaction for words in the lexical decision experiments are $\pm 31 \mathrm{msec}$. That is, we can be reasonably sure that the presence of foils will reduce the priming effect in lexical decision by at least $61 \mathrm{msec}$, whereas a foil manipulation in shadowing can, at most, produce an effect half that size and is just as likely to produce no effect at all.

The effect of foils in a comparison of two lexical decision experiments is, in other words, statistically significant and clearly large enough to be of both theoretical and practical importance. Such effects thus certainly need to be taken into account when designing lexical decision studies of phonologicalpriming. In shadowing experiments of the same power, however, we found no statistically reliable evidence of a strategic effect, and whatever effects might appear in that task are so small as to be of little practical significance. Only the lexical decision task is subject to substantial effects of this nature.

\section{GENERAL DISCUSSION}

Listeners respond more rapidly to target items if they follow primes with which they rhyme. There appear to be two reasons for this. The first is that, in lexical decision tasks, they can develop a bias to say "yes" to targets that rhyme with their primes. The second is that there seems to be a component of the speech recognition system that can benefit from the repeated presentation of spoken items that end in the same way.

In Experiment 1, there was a large and robust rhymepriming effect on lexical decisions to target words, but not to target nonwords. The priming effect with words was severely attenuated when foil items were added in Experiment 2. In lexical decision, therefore, it appears that a bias to respond "yes" to rhyming targets can develop even when there is a relatively low proportion of rhyming trials 
( $25 \%$, of which only half had word targets). This bias would act to mask any other facilitatory effect that might otherwise be seen with nonword targets and to exaggerate any other facilitatory effects with word targets. Although the bias emerges with a relatively low proportion of related trials, it can be removed (or at least considerably reduced) when foil trials are added to the experiment.

In shadowing tasks, in contrast to lexical decision tasks, the foil manipulation failed to significantly reduce the amount of facilitation for rhyming words. Although there was a numerical reduction in the amount of priming (from a mean of $27 \mathrm{msec}$ in Experiment 3 to a mean of $16 \mathrm{msec}$ in Experiment 4), this difference was not statistically significant. Although it is not possible to gainsay strategic bias in shadowing tasks, it is clear that if it exists, it is much weaker than that found in lexical decision tasks. Furthermore, facilitation emerged for rhyming nonwords in shadowing tasks. It would, therefore, appear that in addition to a rhyme-based bias, there is also a component of finaloverlap facilitation that is not strategic.

Other evidence is consistent with this conclusion. First, Slowiaczek et al. (2000), in a continuous lexical decision task with one item intervening between primes and targets, found facilitation for pairs such as wink-PINK with VCC rhymes, but not for pairs such as kiss-MISS with VC rhymes. An all-or-none rhyme bias wrongly predicts equivalent priming for different types of rhyming pairs. Second, Cutler et al. (1999) found facilitation in lexical decision for Dutch words that did not rhyme (e.g., koperKAPER). Third, Slowiaczek et al. (2000) found that facilitation, in both shadowing and lexical decision tasks, tended to increase with increasing phonological overlap; that is, the presence or absence of facilitation did not depend simply on whether or not primes and targets rhymed. The nonstrategic component of final-overlap facilitation, therefore, does not appear to be based purely on rhyme. It may reflect processes in the spoken-word recognition system that precede lexical access.

There are two reasons why the results from the shadowing task should be taken to reflect perceptual processes, rather than production processes, despite the fact that shadowing, of course, requires the use of the speech production system. On the one hand, the facilitation that we observed in the shadowing task is similar to that observed for words in lexical decision tasks when strategic biases are discouraged (Experiment 2) and in identification of noise-masked words (Slowiaczek et al., 1987). Neither of these tasks requires that speech be produced. The differences between lexical decision and shadowing tasks that we observed here (a larger effect in the former task, but one that was specific to words) can be attributed to a rhyme-based bias in lexical decision; there is, nonetheless, agreement between tasks that final overlap leads to facilitation. On the other hand, more importantly, the facilitation we found in shadowing contrasts with the results of phonological priming experiments that have explicitly tested production processes. In a picture-naming task with auditory distractors, Meyer and Schriefers (1991) found no facilitation when distractors that rhymed with the names of the pictures were presented before the pictures. Meyer $(1990,1991)$ did not observe facilitation in naming latencies when the words in the response sets of implicit priming studies ended in the same way. Sullivan and Riffel (1999) observed inhibition when subjects had to name two pictures sequentially: Naming latencies were slower to the second picture when its name rhymed with the name of the first picture than when the picture names were phonologically unrelated. These results all suggest that the nonstrategic component of the facilitation that we observed in Experiments 3 and 4 reflects the effect of phonological overlap between primes and targets on the perceptual system.

\section{Rhyme Bias}

The rhyme bias in phonological priming appears to be based on the perceptual salience of rhyming items (see also Monsell \& Hirsh, 1998; Slowiaczek et al., 2000). Rhyme has an important role to play in learning to read orthographic scripts (e.g., Bradley \& Bryant, 1983; Treiman, Mullennix, Bijeljac-Babic, \& Richmond-Welty, 1995), and it appears to be very salient in various metalinguistic tasks and in many word games (e.g., Treiman, 1983, 1986). We cannot help noticing when words share their ends. This, after all, is the sensitivity on which much of poetry and song depends.

It appears that the listeners in Experiment 1 noticed that primes were sometimes followed by targets with which they rhymed. A bias to respond "yes" when a rhyme was detected (or was predicted to occur, on the basis of the vowel and the beginning of the coda of the target; e.g., ramp-LAM . . .) would thus benefit performance. Note, however, that rhyming nonword targets occurred as often in the experiment as rhyming word targets. Strictly speaking, therefore, rhyme was not predictive of a "yes" response. The bias is therefore unlikely to be a simple response bias. Instead, as Slowiaczek et al. (2000) have suggested, the bias may be based on congruency. A primetarget pair that rhymes is phonologically congruent and is thus consistent with a "yes" response; a pair that does not rhyme is incongruent and thus consistent with a "no" response. In other words, the bias to say "yes" when a rhyme was detected appears to have been driven not by an imbalance in the experimental materials favoring that strategy, but by the inherent congruency of rhyming materials.

The presence of foils, as in Experiment 2, can block this bias. When listeners learn that overlap in the vowels and the onsets of the codas between primes and targets does not predict a rhyme (e.g., they hear bulk-SUL . . . and the target becomes SULSH, not SULK), they appear to suppress any bias based on the congruency of rhyming pairs. However, even in the presence of foils, there is still a small but significant effect of priming. The presence of foils may induce task-specific strategies, such as a checking strategy or an active process of ignoring any phonological 
overlap. These strategies, like the rhyme bias, could also block or mask automatic facilitation effects. The crucial aspect of the foil manipulation, therefore, is not the pattern of results in Experiment 2, but the dramatic change in performance between Experiments 1 and 2. The foil manipulation shows that there was a rhyme bias operating in Experiment 1.

The rhyme bias can influence performance in a binarychoice task like lexical decision in a very straightforward way. It is much less clear how such a bias would influence shadowing performance, where the naming response varies from trial to trial. If the bias acted at the response stage, influencing the speech production processes required for a naming response, it would have to be flexible, in the same sense as the strategy proposed by Goldinger (1998b) for single-phoneme onset overlap facilitation. That is, the bias would need to be reapplied on each trial, so that the encoding of the phonological material for each particular target word could be benefited in some way by the presence of rhyme overlap. It is unclear how such a bias could act, especially since speech production studies suggest that it is the predictability of onset overlap, not offset overlap, that can speed naming latencies (e.g., Meyer, 1990, 1991). A more plausible type of rhyme bias in shadowing, therefore, may be one based on a checking process (cf. Slowiaczek et al., 2000). If listeners check for phonological congruency between primes and targets, the detection of congruency (i.e., a rhyme) could speed responses, or the detection of incongruency could slow responses.

It is not clear, however, whether there are strategic components to rhyme priming in shadowing tasks. On the one hand, the foil manipulation here (Experiments 3 and 4) failed to exert a reliable effect on rhyme priming in the shadowing task. Furthermore, Slowiaczek et al. (2000) did not find a fully robust influence of the number of related trials on the size of the priming effect in a shadowing experiment. On the other hand, there was a numerical, if not statistically significant, reduction in the priming effect when foils were added (Experiment 3 vs. Experiment 4 ), and stronger priming effects in the shadowing task when the targets rhymed with their primes than when they shared the same amount of phonological material but did not rhyme (Slowiaczek et al., 2000). Taken together, these results suggest that, relative to lexical decision, the strategic component of final-overlap facilitation in the shadowing task is quite small. It is most likely to be due to a congruency checking process.

\section{Prelexical Activation}

We suggest that the nonstrategic component of finaloverlap facilitation may reflect the automatic speech perception processes that operate prior to lexical access. Most models of spoken word recognition assume that the process consists of two basic stages. At the first stage, the raw acoustic-phonetic information in the speech signal is decoded. That is, an abstract description of the speaker's articulation is extracted from the speech input. This descrip- tion is then used for lexical access. The second stage of the recognition process involves the activation of multiple candidate words and, as we described in the introduction, competition among those words. The words that win the competition are recognized.

We argue, along with Slowiaczek et al. (2000) and Monsell and Hirsh (1998), that the automatic component of final-overlap facilitation reflects the operation of the first of these two stages, the prelexical stage. When a word (or nonword) is heard, it activates prelexical representations. If a similar-sounding word (or nonword) is then heard, many of the same prelexical representations will be reactivated. If the activation from the first word persists after the acoustic offset of that word, the reactivation process on the second word will be easier (the representations, e.g., could reach a criterial level of activation more rapidly) than when the first word was phonologically unrelated. Because this prelexical mechanism does not depend on stored lexical knowledge, it predicts more or less equivalent priming for words and nonwords (as was observed in Experiments 3 and 4 and by Cutler et al., 1999, Dumay et al., 2001, Monsell \& Hirsh, 1998, and Slowiaczek et al., 2000). It also correctly predicts that facilitation should be observed when both primes and targets are spoken, but not when primes are spoken but targets are visual (Cutler et al., 1999; Radeau et al., 1994) or when primes are visual and targets are spoken (Dumay et al., 2001). Furthermore, this account is consistent with the finding that the relative frequency of primes and targets does not influence the amount of facilitation (Radeau et al., 1995).

This prelexical mechanism does not predict facilitation effects when primes and targets overlap in their onsets. Although there should be persistence of activation of prelexical representations for segmental material at the beginnings and ends of words, the facilitatory effects of this prelexical activation when primes and targets share their onsets will be masked by the inhibitory effects of lexical competition. A target word that begins in the same way as a prime will be activated when that prime is heard but will then be penalized as it loses the lexical competition. As Monsell and Hirsh (1998) and Slowiaczek et al. (2000) have argued, the combined influences of prelexical facilitation and lexical inhibition may be one reason that it has been hard to observe robust inhibitory effects in phonological priming given multiple-phoneme onset overlap. Note, also, that one reason that facilitatory effects can be observed when primes and targets rhyme is that the lexical representations of target words will not be strongly activated, if at all, by primes with which they rhyme (MarslenWilson, Moss, \& van Halen, 1996). If they are not involved in the lexical competition process, they will not be inhibited, allowing the facilitatory effects of the activation of prelexical representations to be observed.

Models of word recognition disagree about the nature of the representations at the prelexical level of processing. In PARSYN (Luce et al., 2000), the representations are allophones. In Shortlist (Norris, 1994), they are phonemes, 
whereas in the distributed cohort model (Gaskell \& MarslenWilson, 1997), they are featural. TRACE (McClelland \& Elman, 1986) has both of these options: a featural stage followed by a phonemic stage. Although the results from phonological priming experiments do not allow us to distinguish between these alternatives, they do suggest two things. First, they suggest that prelexical representations are sufficiently abstract to code the fact that there is phonological overlap between different tokens of different words. Second, and more generally, they suggest that there is some level of processing that mediates between the speech signal and the mental lexicon. A strong version of the episodic model, in which each individual token of each word is separately stored (Goldinger, 1996, 1998a), is therefore challenged by these findings. Such a model would appear to require the addition of a stage of processing with sufficient capacity for abstraction and normalization to be able to capture the fact that rhyming words share phonological material.

\section{Word Versus Nonword Targets}

The account of the pattern of results for word targets is therefore quite straightforward. In shadowing, there is no significant bias component to the facilitation. The priming effect appears to reflect primarily the persistence of activation of prelexical representations. In lexical decision, this automatic priming effect is supplemented by a bias to respond "yes" when primes and targets rhyme, producing a large facilitatory effect (Experiment 1), unless that bias is discouraged by the presence of foils (Experiment 2). In this case, the foils may themselves induce some other strategy (based, perhaps, on checking or, perhaps, on ignoring phonological overlap), preventing a clear automatic facilitation effect from being seen.

Even though the findings for nonword targets are quite different from those for word targets, they are consistent with this account. In the shadowing task, where there was no strong bias favoring rhyming words, facilitation was found for nonwords. This, we argue, again reflects persisting activation at the prelexical level. In the lexical decision task, when there were no foils, the effects of this activation were not observed, because of the rhyme bias favoring "yes" responses. But why was there no facilitation for nonwords in the lexical decision task when foils blocked the use of a strategic bias? Note that whereas the size of the facilitation effect for words in the lexical decision task dropped from an average of $118 \mathrm{msec}$ in Experiment 1 to an average of $27 \mathrm{msec}$ in Experiment 2, there was no real change in the pattern for nonwords (mean inhibitory effects of -3 and $-7 \mathrm{msec}$, respectively). If the bias was reduced for words between these two experiments, why was there no trace of a facilitatory effect for the nonwords in Experiment 2?

The answer may be that, as with word targets, the foils themselves induced some kind of strategic processing and thus blocked detection of an automatic facilitatory effect. The nature of "no" decisions in the lexical decision task might, however, prevent detection of any benefit that was due to prelexical processes in nonword decisions, even if neither biases that were due to rhyme nor biases that were due to foils were operating. A "yes" decision reflects the activation of a single lexical representation, but a "no" decision reflects the lack of sufficient activation of any words (and thus takes more time). Since persistence in activation of prelexical representations will boost the activation of words (those rhyming with the prime and the target) when a nonword target is presented, "no" decisions will tend to be slowed down. (Nonsignificant inhibitory trends for nonword targets were indeed found in Experiments 1 and 2 and in some conditions in Monsell \& Hirsh, 1998.) Persistence of prelexical activation may thus tend to have an inhibitory, rather than a facilitatory, effect on "no" responses in lexical decision.

\section{Conclusions}

We have argued that the facilitation that is observed when spoken-word targets rhyme with preceding primes has both strategic and automatic components. Previous research had distinguished both strategic and automatic components in the priming effects observed when primes and targets begin in the same way. Phonological priming involving initial overlap and phonological priming involving final overlap thus present a similar mixture of origins; priming certainly reflects necessary, automatic aspects of the recognition process, but it is also sensitive to situationspecific changes in behavior as listeners strive to optimize their performance in experiments.

The relative contributions of strategic and automatic components in final-overlap facilitation vary as a function of the experimental task, the presence or absence of foil trials (targets that just fail to rhyme with their primes), and the lexical status of the target items. In lexical decision, listeners can develop a bias to say "yes" when primes and targets rhyme. This bias facilitates responses to words and inhibits responses to nonwords. The presence of foils strongly discourages the use of such a bias. In the shadowing task, in contrast, there appears to be no such strong likelihood of bias developing. Clearer automatic effects can therefore be observed in this task. These effects reflect the persistence of activation of prelexical representationsthat is, the mental representations that map between an acoustic representation of the speech signal and the mental lexicon.

\section{REFERENCES}

Allopenna, P. D., Magnuson, J. S., \& Tanenhaus, M. K. (1998). Tracking the time course of spoken word recognition using eye movements: Evidence for continuous mapping models. Journal of Memory \& Language, 38, 419-439.

Bradley, L., \& BRYANT, P. E. (1983). Categorizing sounds and learning to read: A causal connection. Nature, 301, 419-421.

Burnage, G. (1990). CELEX: A guide for users. Nijmegen: CELEX.

Cutler, A., \& Chen, H.-C. (1995). Phonological similarity effects in Cantonese word recognition. In K. Elenius \& P. Branderud (Eds.), Proceedings of the 13th International Congress of Phonetic Sciences 
(Vol. 1, pp. 106-109). Stockholm: Kungliga Tekniska Högskolan and Stockholm University.

Cutler, A., van Ooijen, B., \& Norris, D. (1999). Vowels, consonants and lexical activation. In J. J. Ohala, Y. Hasegawa, M. Ohala, D. Granville, \& A. C. Bailey (Eds.), Proceeding s of the 14th International Congress of Phonetic Sciences (Vol. 3, pp. 2053-2056). Berkeley: University of California.

Dahan, D., Magnuson, J. S., Tanenhaus, M. K., \& Hogan, E. M. (2001). Subcategorical mismatches and the time course of lexical access: Evidence for lexical competition. Language \& Cognitive Processes, 16, 507-534.

Dumay, N., Benraïss, A., Barriol, B., Colin, C., Radeau, M., \& Besson, M. (2001). Behavioral and electrophysiological study of phonological priming between bisyllabic spoken words. Journal of Cognitive Neuroscience, 13, 121-143.

Emmorey, K. D. (1989). Auditory morphological priming in the lexicon. Language \& Cognitive Processes, 4, 73-92.

Gaskell, M. G., \& MARSLEN-Wilson, W. D. (1997). Integrating form and meaning: A distributed model of speech perception. Language \& Cognitive Processes, 12, 613-656.

GolDINGER, S. D. (1996). Words and voices: Episodic traces in spoken word identification and recognition memory. Journal of Experimental Psychology: Learning, Memory, \& Cognition, 22, 1166-1183.

Goldinger, S. D. (1998a). Echoes of echoes? An episodic theory of lexical access. Psychological Review, 105, 251-279.

GoldingER, S. D. (1998b). Signal detection comparisons of phonemic and phonetic priming: The flexible-bias problem. Perception \& Psychophysics, 60, 952-965.

Goldinger, S. D. (1999). Only the Shadower knows: Comment on Hamburger and Slowiaczek (1996). Psychonomic Bulletin \& Review, 6, 347-351.

Goldinger, S. D., Luce, P. A., \& Pisoni, D. B. (1989). Priming lexical neighbors of spoken words: Effects of competition and inhibition. Journal of Memory \& Language, 28, 501-518.

Goldinger, S. D., Luce, P. A., Pisoni, D. B., \& Marcario,J. K. (1992). Form-based priming in spoken word recognition: The roles of competition and bias. Journal of Experimental Psychology: Learning, Memory, \& Cognition, 18, 1211-1238.

Hamburger, M., \& Slowiaczek, L. M. (1996). Phonological priming reflects lexical competition. Psychonomic Bulletin \& Review, 3, 520525 .

Hamburger, M., \& Slowiaczek, L. M. (1999). On the role of bias in dissociated phonological priming effects: A reply to Goldinger (1999). Psychonomic Bulletin \& Review, 6, 352-355.

Luce, P. A., Goldinger, S. D., Auer, E. T., Jr. \& Vitevitch, M. S. (2000). Phonetic priming, neighborhood activation, and PARSYN. Perception \& Psychophysics, 62, 615-625.

Luce, P. A., \& LARge, N. R. (2001). Phonotactics, density, and entropy in spoken word recognition. Language \& Cognitive Processes, 16, 565581 .

Marslen-Wilson, W., Moss, H. E., \& van Halen, S. (1996). Perceptual distance and competition in lexical access. Journal of Experimental Psychology: Human Perception \& Performance, 22, 1376-1392.

McClelland, J. L., \& Elman, J. L. (1986). The TRACE model of speech perception. Cognitive Psychology, 10, 1-86.

McQueen, J. M., Norris, D., \& Cutler, A. (1994). Competition in spoken word recognition: Spotting words in other words. Journal of Experimental Psychology: Learning, Memory, \& Cognition, 20, 621 638.

Meyer, A. S. (1990). The time course of phonological encoding in language production: The encoding of successive syllables of a word Journal of Memory \& Language, 29, 524-545.

Meyer, A. S. (1991). The time course of phonological encoding in language production: Phonological encoding inside a syllable. Journal of Memory \& Language, 30, 69-89.

Meyer, A. S., \& Schriefers, H. (1991). Phonological facilitation in picture-word interference experiments: Effects of stimulus onset asynchrony and types of interfering stimuli. Journal of Experimental Psychology: Learning, Memory, \& Cognition, 17, 1146-1160.

MONSELl, S., \& HIRSH, K. W. (1998).Competitor priming in spoken word recognition. Journal of Experimental Psychology: Learning, Memory, \& Cognition, 24, 1495-1520.

NoRRIS, D. (1984). A computer-based programmable tachistoscope for nonprogrammers. Behavior Research Methods, Instruments, \& Computers, 16, 25-27.

Norris, D. (1994). Shortlist: A connectionist model of continuous speech recognition. Cognition, 52, 189-234.

Norris, D., McQueen, J. M., \& Cutler, A. (1995). Competition and segmentation in spoken-word recognition. Journal of Experimental Psychology: Learning, Memory, \& Cognition, 21, 1209-1228.

Praamstra, P., Meyer, A. S., \& Levelt, W. J. M. (1994). Neurophysiological manifestations of phonological processing: Latency variation of a negative ERP component time-locked to phonological mismatch. Journal of Cognitive Neuroscience, 6, 204-219.

Radeau, M., Besson, M., Fontaneau, E. \& Castro, S. L. (1998). Semantic, repetition, and rime priming between spoken words: Behavioral and electrophysiological evidence. Biological Psychology, 48, 183-204.

Radeau, M., Morais, J., \& Dewier, A. (1989). Phonological priming in spoken word recognition: Task effects. Memory \& Cognition, 17, 525-535.

Radeau, M., Morais, J., \& Seguí, J. (1995). Phonological priming between monosyllabic spoken words. Journal of Experimental Psychology: Human Perception \& Performance, 21, 1297-1311.

Radeau, M., Seguí, J., \& Morais, J. (1994). The effect of overlap position in phonological priming between spoken words. In Proceedings of the 1994 International Conference on Spoken Language Processing (Vol. 3, pp. 1419-1422). Yokohama: Acoustical Society of Japan.

SlowiaczeK, L. M., \& Hamburger, M. (1992). Prelexical facilitation and lexical interference in auditory word recognition. Journal of Experimental Psychology: Learning, Memory, \& Cognition, 18, 12391250.

Slowiaczek, L. M., McQueen, J. M., Soltano, E. G., \& Lynch, M. (2000). Phonological representations in prelexical speech processing: Evidence from form-based priming. Journal of Memory \& Language, 43, 530-560.

Slowiaczek, L. M., Nusbaum, H. C., \& Pisoni, D. B. (1987). Phonological priming in auditory word recognition. Journal of Experimental Psychology: Learning, Memory, \& Cognition, 13, 64-75.

SLOWIACZEK,L. M., \& Pisoni, D. B. (1986). Effects of phonological similarity on priming in auditory lexical decision. Memory \& Cognition, 14, 230-237.

Soto-Faraco, S., Sebastián-Gallés, N., \& Cutler, A. (2001). Segmental and suprasegmental mismatch in lexical access. Journal of Memory \& Language, 45, 412-432.

Sullivan, M. P., \& Riffel, B. (1999). The nature of phonological encoding during spoken word retrieval. Language \& Cognitive Processes, 14, 15-45.

Trtone, D., \& Connine, C. M. (1997). Syllabification strategies in spoken word processing: Evidence from phonological priming. Psychological Research, 60, 251-263.

Treiman, R. (1983). The structure of spoken syllables: Evidence from novel word games. Cognition, 15, 49-74.

Treiman, R. (1986). The division between onsets and rimes in English syllables. Journal of Memory \& Language, 25, 476-491.

Treiman, R., Mullennix, J., Bijeljac-Babic, R., \& RichmondWelty, E. D. (1995). The special role of rimes in the description, use and acquisition of English orthography. Journal of Experimental Psychology: General, 124, 107-136.

Vitevitch, M. S., \& Luce, P. A. (1998). When words compete: Levels of processing in spoken word recognition. Psychological Science, $\mathbf{9}$, 325-329.

Vitevitch, M. S., \& Luce, P. A. (1999). Probabilistic phonotactics and neighborhood activation in spoken word recognition. Journal of Memory \& Language, 40, 374-408.

Vroomen, J., \& DE Gelder, B. (1995). Metrical segmentation and lexical inhibition in spoken word recognition. Journal of Experimental Psychology: Human Perception \& Performance, 21, 98-108.

ZWitserlood, P. (1989). The locus of the effects of sentential-semantic context in spoken-word processing. Cognition, 32, 25-64. 


\section{APPENDIX}

\section{Materials for All Four Experiments}

Note-The foil fillers appeared with unrelated primes in Experiments 1 and 3, and with foil primes in Experiments 2 and 4.

\section{Target Words}

\begin{tabular}{|c|c|c|c|c|c|}
\hline Rhyming Prime & Unrelated Prime & Target & Rhyming Prime & Unrelated Prime & Target \\
\hline wrench & limp & bench & fact & jump & backed \\
\hline fend & lift & bend & went & fact & bent \\
\hline hinge & rest & binge & chest & romp & best \\
\hline shelve & pinch & delve & felled & damp & welled \\
\hline left & valve & theft & damp & went & camp \\
\hline tilt & shelve & guilt & romp & sheds & chomp \\
\hline land & felt & hand & sheds & silk & heads \\
\hline wealth & jabbed & health & list & yelled & fist \\
\hline realm & wince & helm & shift & whelp & gift \\
\hline shopped & tank & hopped & yelled & shift & held \\
\hline felt & ramp & knelt & whelp & wisp & kelp \\
\hline jabbed & left & dabbed & jump & hint & bump \\
\hline tenth & shopped & length & mend & wink & lend \\
\hline pink & realm & $\operatorname{link}$ & wisp & mend & lisp \\
\hline pinch & popped & lynch & pelt & tinge & melt \\
\hline popped & tenth & mopped & silk & test & milk \\
\hline rest & land & pest & mince & pelt & since \\
\hline limp & fend & pimp & tinge & felled & singe \\
\hline scent & hinge & rent & vent & mince & tent \\
\hline lift & wealth & rift & wink & chest & think \\
\hline wince & scent & rinse & hint & pulp & tint \\
\hline valve & wrench & salve & test & shunned & vest \\
\hline $\operatorname{tank}$ & tilt & sank & pulp & vent & gulp \\
\hline ramp & pink & lamp & shunned & list & fund \\
\hline \multicolumn{6}{|c|}{ Target Nonwords } \\
\hline Rhyming Prime & Unrelated Prime & Target & Rhyming Prime & Unrelated Prime & Target \\
\hline band & wilt & thanned & lint & talc & rint \\
\hline bank & bust & vank & sieved & junk & nived \\
\hline wilt & bunk & yilt & lymph & once & pymph \\
\hline bunk & sect & runk & mist & hunch & vist \\
\hline bust & bank & shust & monk & sieved & vunk \\
\hline yank & jilt & pank & dusk & leant & fusk \\
\hline cost & funk & shost & nest & want & thest \\
\hline tend & dunk & shend & once & tact & lonce \\
\hline dense & rump & bense & pact & lint & vact \\
\hline $\operatorname{din} t$ & hump & fint & hunch & pact & junch \\
\hline dunk & fix & thunk & rank & soft & fank \\
\hline month & wasp & lunth & leant & rusk & fent \\
\hline fix & dint & shicks & runt & rank & thunt \\
\hline fond & husk & lond & rusk & font & shusk \\
\hline rump & kink & fump & font & lymph & sont \\
\hline funk & cost & lunk & sink & nest & gink \\
\hline wasp & tend & dosp & soft & chink & foft \\
\hline hilt & yank & filt & tact & monk & dact \\
\hline hump & hilt & vump & talc & runt & balc \\
\hline sect & fond & mect & junk & mist & nunk \\
\hline husk & dense & gusk & tuft & $\sin k$ & duft \\
\hline jilt & month & rilt & want & dusk & bont \\
\hline kink & lost & dink & chink & waste & bink \\
\hline lost & band & fost & waste & tuft & daste \\
\hline
\end{tabular}


APPENDIX (Continued)

\begin{tabular}{|c|c|c|c|c|c|}
\hline \multicolumn{6}{|l|}{ Foil Fillers } \\
\hline Foil Prime & Unrelated Prime & Word Target & Foil Prime & Unrelated Prime & Nonword Target \\
\hline dump & depth & numbed & meant & silt & benk \\
\hline bulb & pond & sulk & silt & rust & bilm \\
\hline film & dump & kilt & messed & lunch & chesk \\
\hline pulse & film & gulf & wand & kissed & fonk \\
\hline self & shunt & belch & bond & dust & conth \\
\hline shunt & self & dunce & kissed & belt & hisp \\
\hline sift & solve & fifth & lunch & wept & hunned \\
\hline solve & busk & golf & wept & wand & keps \\
\hline send & hummed & gent & finch & thump & linned \\
\hline depth & hunt & leapt & rink & bulk & lins \\
\hline chimp & cult & dimmed & mint & messed & hink \\
\hline pond & whisp & honk & cinch & hence & linth \\
\hline cult & send & bulge & rust & cinch & lusk \\
\hline busk & hanged & gust & punch & finch & munse \\
\hline hunt & shelf & bunch & dust & rink & musp \\
\hline hummed & sense & lump & lust & $\operatorname{mint}$ & busp \\
\hline lunge & sift & munch & belt & penned & nelp \\
\hline whisp & bulb & risk & winch & lust & pinth \\
\hline hanged & lunge & shank & pox & winch & bocked \\
\hline hulk & chimp & gulls & penned & bond & senth \\
\hline sense & hulk & vend & thump & meant & rummed \\
\hline shelf & pulse & meld & hissed & punch & sisp \\
\hline kicked & sand & $\operatorname{mix}$ & bulk & pox & sulsh \\
\hline sand & kicked & thank & hence & hissed & tenk \\
\hline \multicolumn{6}{|l|}{ Other Fillers } \\
\hline Unrelated Prime & Word Target & Unrelated Prime & Nonword Target & & \\
\hline beds & chipped & bagged & jolm & & \\
\hline mashed & coughs & banged & vutch & & \\
\hline bobbed & hemp & pigs & vulk & & \\
\hline bids & tusk & bats & lutch & & \\
\hline bunged & nymph & pushed & nift & & \\
\hline buzzed & mops & shoved & masp & & \\
\hline $\operatorname{mink}$ & sobbed & cuffs & dalm & & \\
\hline cups & licked & rubbed & plosh & & \\
\hline cyst & dubbed & ribbed & hussed & & \\
\hline dashed & tongues & duct & kemmed & & \\
\hline dipped & gunge & bins & futch & & \\
\hline buds & whelk & tapped & vulled & & \\
\hline chips & fanned & gelled & bolve & & \\
\hline fills & locked & fits & yuld & & \\
\hline goods & west & fizzed & nemp & & \\
\hline tugs & pitched & zinc & sheft & & \\
\hline hitched & fox & lens & spish & & \\
\hline hushed & wench & must & pelled & & \\
\hline jogged & bells & wrecks & volled & & \\
\hline kings & chucked & hedged & dunth & & \\
\hline lapped & dots & hips & monch & & \\
\hline pills & cooked & lobbed & misk & & \\
\hline puffed & ships & judged & flish & & \\
\hline wolf & quint & musk & ninned & & \\
\hline
\end{tabular}

